\title{
Screening of Lactic Acid Bacteria for Antifungal Activity against Fungi
}

\author{
Merih Kıvanc ${ }^{1 *}$, Sertac Argun Kıvanc ${ }^{2}$ and Selma Pektas
}

${ }^{1}$ Anadolu University, Faculty of Science, Department of Biology, Eskisehir, Turkey

${ }^{2}$ Uludag University, School of Medicine, Department of Ophthalmology, Bursa, Turkey

\begin{abstract}
Many chemical preservatives that target fungi growth in food have been approved and used for many years. Recently the consumers are looking and demanding for products without chemical preservatives and still maintain good shelf life and safe. The growth of spoilage fungi have been a global concern because of the economy loses and the health hazard of the mycotoxins produced by the spoilage fungi. A total of 22 lactic acid bacteria isolated from Tarhana and Lactic acid bacteria were screened for antifungal activity using dual agar overlay method and well method against Alternaria alternata, Aspergillus parasiticus, Aspergillus oryzae Penicillium griseofulvum, Penicillium chrysogenum, Penicillium notatu, Penicillium citrinum, Penicillium roquefort, Aspergillus fumigatus. Ten isolates showed inhibition activity after $72 \mathrm{~h}$ incubation at $30^{\circ} \mathrm{C}$. Supernatant of 10 isolates with strong antifungal activity was evaluated by well method and they inhibited the growth of the fungi at $30^{\circ} \mathrm{C}$ for $72 \mathrm{~h}$. F2,1 supernatant reduced the mass growth of Penicillium griseofulvum, Penicillium chrysogenum Aspergillus fumigatus and Aspergillus parasiticus when incubated for 6 days at $30^{\circ} \mathrm{C}$. The isolates were identified using rapid ID 32 Strep as Enterococcus durans F2.1. F2.1 isolates studied inhibited the growth of the mycelia and conidia germination of the fungi which indicate the possibility of using $\mathrm{LAB}$ isolates as biopreservative.
\end{abstract}

Keywords: Antifungal; Enterococcus durans; Lactic acid bacteria

\section{Introduction}

Moulds are common spoilage organisms in different food and feed products. This spoiling moulds cause great economic losses worldwide. Food and feed contamination by fungi and by their mycotoxins constitute potential health hazard to consumers [1]. The inhibition of growth of fungi in foods remains a big challenge for food industries.

Many physical and chemical methods have been developed inhibiting of fungi for many years. Lactic acid bacteria contribute technological and nutritional properties and influence the food. They also extend the microbiological shelf-life of final products. Lactic Acid Bacteria (LAB) produce antimicrobial compounds which can be applied as food preservatives. Biopreservation refers to extended shelflife and enhanced safety of foods obtained by the natural or added microflora or their antimicrobial products [1]. Lactic acid bacteria (LAB) have traditionally been used as natural biopreservatives in food and animal feed. Using microorganisms in order to control the fungi growth appears as a good alternative [2]. Lactic acid bacteria (LAB) have received much attention, especially because of their food grade and their GRAS status $[3,4]$. LABs preserving effect relates mainly to the formation of organic acids such as lactic and acetic acid and hydrogen peroxide, competition for nutrients and production of antimicrobial substances and bacteriocins, phenyllactic (PLA) and $p$-OH-phenyllactic acids (OH-PLA), caproic acid or reuterin $[1,2,5]$.

The objective of this study is to evaluate the antifungal activity of LAB isolated from fermented food tarhana. Further, this study was to evaluate the behaviour of Lactic acid bacteria and fungi. The bacteria and their products can be applied as biopreservatives.

\section{Material and Methods}

\section{Chemical materials}

Malt extract agar (MEA), Lactobacillus Broth acc. to DE MAN, ROGOSA and SHARPE( MRS broth), Lactobacillus Agar acc. to DE MAN, ROGOSA and SHARPE (MRS agar) potato dextrose agar (PDA), Tween $80, \mathrm{NaCl}$, hydrogen peroxide, L-Arginine were purchased from Merck (Turkey). Czapek-Dox Agar and Yeast Extract purchased from Difco (Turkey). All other chemicals and reagents used were of analytical grade unless otherwise stated.

RiboPrinter ${ }^{\circledast}$ System disposables ( Sample carriers and buffer, Colony picks, Gel cassettes and membranes, Restriction enzymeschoose EcoRI, Lysing agents, Probes, including IS6110, Conjugate, base and substrate, DNA prep pack) were obtained from DuPont ${ }^{\text {tw }}$ and ID 32 Strep and Blood agar plates were obtained from Biomeriux (Turkey).

\section{Microorganisms}

Twenty two LAB strains (F 5,3; F4,4; F5,4; F7,4; 2F3,2; F7,2; 2F5,7; F6,4,1; F6,2,3; F6,2,2,3; F6,4,2; F3,2; F7,8; F2,1; 2F2,2; 2F7,5; 2F4,1; $\mathrm{F} 7,1,2 ; 2 \mathrm{~F} 4,2 ; 2 \mathrm{~F} 5,3)$ isolated from tarhana were obtained from the University of Anadolu, Faculty of Science (Eskişehir, Turkey). Frozen cultures of these lactobacilli were transferred into MRS broth (Merck, Darmstadt, Germany) using $1 \%$ inoculum and incubated at $30^{\circ} \mathrm{C}$ for 24 h. before use, they were subcultured at least twice.

\section{Fungal cultures and preparation of the spore solution}

The moulds Penicillium roqueforti, Alternaria alternata, Penicillium notatum, Penicillium citrinum, Aspergillus parasiticus, Penicillium chrysogenum, Penicillium griseofulvum, Aspergillus fumigatus, Aspergillus oryzae (University of Anadolu, Faculty of Science Eskişehir, Turkey) were used in this study for assay of antifungal activity in vitro.

Moulds were cultivated on Malt Extract Agar (MEA) (Merck,

*Corresponding author: Merih Kıvanc, Anadolu University, Faculty of Science, Department of Biology, Eskisehir, Turkey, Tel: 7842635534; E mail: mkivanc@anadolu.edu.tr

Received March 05, 2014; Accepted March 24, 2014; Published April 03, 2014

Citation: Kivanc M, Kivanc SA, Pektas S (2014) Screening of Lactic Acid Bacteria for Antifungal Activity against Fungi. J Food Process Technol 5: 310. doi:10.4172/2157-7110.1000310

Copyright: ( $) 2014$ KIvanc M, et al. This is an open-access article distributed unde the terms of the Creative Commons Attribution License, which permits unrestricted use, distribution, and reproduction in any medium, provided the original author and source are credited. 
Darmstadt, Germany) at $25^{\circ} \mathrm{C}$ for 2 to 5 days and stored at $4^{\circ} \mathrm{C}$. The fungi strains were grown on malt extract agar (MEA) at $25^{\circ} \mathrm{C}$ for 7 days. The conidia were collected in sterile Tween 80 (Merck, Darmstadt, Germany) at $0.05 \%(\mathrm{v} / \mathrm{v})$ and counted at the microscope in a haemocytometer chamber. Collection fluid was used to adjust to $10^{6}$ spores / $\mathrm{mL}$.

\section{Screening of bacteria for antifungal activity}

Bacterial isolates, grown in $10 \mathrm{ml}$ of MRS broth at $35^{\circ} \mathrm{C}$ overnight, were tested for their antifungal activity against fungi as an initial screening step. Two different assays, the overlay method and the dual-culture agar overlay method were employed to detect antifungal activity.

The antifungal activity of LAB was investigated with an overlay assay [6,7]. Bacteria were inoculated in 2-cm lines on MRS agar plates and allowed to grow at $30^{\circ} \mathrm{C}$. Ten millilitre of soft $(7 \%)$ malt extract agar containing $1 \mathrm{ml}$ of inoculum of mould spore was then poured onto the agar plates and incubated at $30^{\circ} \mathrm{C}$. After $48 \mathrm{~h}$, the zone of inhibition was measured. The degree of inhibition was calculated as the area of inhibited growth.

Other method dual-culture agar overlay method, LAB strains were inoculated into MRS agar and poured plate and plates allowed growing at $30^{\circ} \mathrm{C}$ for up to $2-3$ days in anaerobic jars. The plates then were overlaid with MEA $(0.7 \%, 5 \mathrm{ml})$. Spotting $5 \mu \mathrm{l}$ of containing about $10^{5}$ spores of fungi per ml onto the surface of a MEA plate. After incubation for up to 9 days at $25^{\circ} \mathrm{C}$, the plates were examined for the formation of inhibition zones around the bacterial colonies. The plates were examined for zones of inhibition in the test fungi.

\section{Determination of inhibitory activity of cell-free supernatants}

$\mathrm{LAB}$ was inoculated to an initial concentration of $10^{6} \mathrm{cfu} / \mathrm{mL}$ in $50 \mathrm{~mL}$ of MRS broth ( $\mathrm{pH} \mathrm{6.5)}$ and was incubated at $35^{\circ} \mathrm{C}$ for 48 h. Afterwards, broth culture was centrifuged at $5000 \times \mathrm{g}$ for $15 \mathrm{~min}$ at $4^{\circ} \mathrm{C}$ and cell-free supernatants were filtrated $(0.22 \mu \mathrm{m}$ pore size filter; Millipore).

The Czapek-Dox Agar-Yeast Extract (Czapek Dox agar (Difco) w/ $1.0 \%$ yeast extract (Difco)) was rapidly dispensed in sterile petri dishes and, after solidification. Wells of $8 \mathrm{~mm}$ diameter were cork bored in the agar and a droplet of agar was added to each well. $80 \mu \mathrm{L}$ of sterilized cell-free supernatants were dispensed in the wells and allowed to diffuse into the agar during a 2 -h pre-incubation period at room temperature. Small portion of five day-old mycelia of fungi were placed in the middle of a Czapek-Dox Agar-Yeast Extract agar plate. Plates were incubated overnight at $30^{\circ} \mathrm{C} 9 \mathrm{~d}$. Mycelia growth zone was measured by diameter.

\section{Inhibition of tested moulds by $E$. durans F2.1 in MRS broth}

The MRS broth was inoculated with $1 \%(\mathrm{v} / \mathrm{v})$ fungi $\left(10^{5} \mathrm{spore} / \mathrm{ml}\right.$ from with (treatment) and without (control) the addition of $1 \% \mathrm{v} / \mathrm{v}$ LAB (initial cell count in the inoculated MRS broth was approximately $10^{6} \mathrm{cfu} / \mathrm{mL}$ ). $20-\mathrm{mL}$ inoculated MRS broth were incubated at $30^{\circ} \mathrm{C}$ for 5 days. Samples from each tube removed at different time and plated to count. Microbial counts, decimal dilutions were prepared in sterile 9 $\mathrm{ml}$ of $0.85 \%(\mathrm{w} / \mathrm{v}) \mathrm{NaCl}$ (Merck, Darmstadt, Germany) and plated on media. The number of colony forming units $(\mathrm{cfu} / \mathrm{g}$ ) was determined by plate count procedure in MRS agar for LAB and potato dextrose agar (PDA) (Merck, Darmstadt, Germany) for enumeration of fungi. Plates were incubated at $30^{\circ} \mathrm{C}$ for $24 \mathrm{~h}$, and then counted for viable organisms.

\section{Identification of isolate F2.1}

Isolate F2.1 were identified using the catalase, ammonia production from arginine, alpha hemolysis, beta hemolysis, growth at different temperatures $\left(4,10,15\right.$ and $\left.45^{\circ} \mathrm{C}\right)$, growth at different $\mathrm{pH}$ values, growth at different $\mathrm{NaCl}$ concentrations [8,9]. Carbohydrate fermentation tests were carried out using the rapid ID 32 Strep according to the manufacturer's instruction (BioMerieux, France). Automatic ribotyping was performed with a RiboPrinter ${ }^{\circledast}$ Microbial Characterization System (Qualicon Inc., Wilmington, DE)

\section{Results and Discussion}

Screening of the $22 \mathrm{LAB}$ were performed against pathogenic fungi growth in vitro. Varying degrees of inhibition were detected against the moulds in the overlay method. P. chrysogenum was the most sensitive strain (Table 1). Ten of the 22 isolates showed good inhibitory activity against of the fungi in the overlay method. Of these 22 LAB strains, seven exhibited inhibitory effects tested fungi in dual-culture agar overlay methods (Table 2). Alternaria alternata was the most sensitive strain in dual-culture agar overlay methods.

Ten isolates (10/22) had inhibitory against spore germination and the mycelia growth of tested fungi (Table 3). LAB isolated from tarhana showed good inhibition activity against mycelia growth tested.

In this study we observed that the antifungal activity was straindependent as well as the evaluated fungal species and tested methods.

The growth of the mycelia and the conidia were inhibited by the supernatant of the LAB isolates by the well method. Growth of the mycelia was inhibited and there was no conidia forming observed from the survived mycelia.

L. rhamnosus was reported to inhibit the growth of Aspergillus, Penicillium and Fusarium [10]. Muhialdin and Hassan [11] reported that LAB isolated from fermented guava juice inhibited the spore germination and mycelia growth of A.oryzae.

From the total of LAB strains evaluated, F2,1 isolate was selected due to their inhibitory effect on all fungal strains tested. The F 2.1 isolate were identified using rapid ID 32 Strep as Enterococcus durans (Table 4) and it was confirmed by EcoRI ribotyping (Figure 1). Enterococcus spp. are rarely described to antifungal activities [12-14]. E. durans $\mathrm{F}$ 2.1 has antagonistic effects against tested fungal strains. E. durans A5-

\begin{tabular}{|c|c|c|}
\hline Molds & Lactic acid bacteria & Antifungal activity \\
\hline Alternaria alternata & F 7.4 & + \\
\hline Aspergillus fumigatus & F 7.4 & + \\
\hline & F 7.4 & + \\
Aspergillus oryzae & F 7.5 & ++ \\
\hline Aspergillus parasiticus & F 3.2 & + \\
\hline Penicillium citrinum & F 2.1 & + \\
\hline & F 7.4 & + \\
\hline Penicillium chrysogenum & F 7.2 & +++ \\
& F 5.4 & ++ \\
\hline Penicillium griseofulvum & 2 F 7.5 & +++ \\
\hline Penicillium notatum & F 2.1 & +++ \\
\hline Penicillium roqueforti & F 3.2 & +++ \\
\hline
\end{tabular}

$(+)$ weak inhibition ( İnhibition zone $\leq 0.5 \mathrm{~mm}$ ), (++)modarate inhibition ( İnhibition zone $0.6-1.4 \mathrm{~mm}$ )

$(+++)$ İnhibition zone 1.5- $2.4 \mathrm{~mm},(++++)$ İnhibition zone.$\geq 2.5 \mathrm{~mm}$

Table 1: Antifungal inhibition spectrum of $L A B$ strains in a overlay methods. 
Citation: Kıvanc M, Kıvanc SA, Pektas S (2014) Screening of Lactic Acid Bacteria for Antifungal Activity against Fungi. J Food Process Technol 5: 310. doi:10.4172/2157-7110.1000310

Page 3 of 4

\begin{tabular}{|c|c|c|c|c|c|}
\hline Strains & $\begin{array}{c}\boldsymbol{P} \\
\text { chrysogenum }\end{array}$ & $\begin{array}{c}\boldsymbol{A} \\
\text { parasiticus }\end{array}$ & $\begin{array}{c}\boldsymbol{P} \text { griseofulvum } \\
\text { fumigatus }\end{array}$ & $\begin{array}{c}\boldsymbol{A} . \\
\text { alternata }\end{array}$ \\
\hline $\mathrm{F} 5,3$ & - & + & ++ & - & - \\
\hline $\mathrm{F} 4,4$ & + & ++ & +++ & ++ & - \\
\hline $\mathrm{F} 5,4$ & - & - & ++ & - & - \\
\hline $\mathrm{F} 7,4$ & + & ++ & ++ & ++ & - \\
\hline $2 \mathrm{~F} 3,2$ & + & - & ++ & ++ & - \\
\hline $\mathrm{F} 7,2$ & - & - & ++ & - & - \\
\hline $2 \mathrm{~F} 5,7$ & ++ & - & + & - & + \\
\hline $\mathrm{F} 6,4,1$ & +++ & ++ & ++ & ++ & - \\
\hline $2 \mathrm{~F} 7,1$ & +++ & - & ++ & - & - \\
\hline $\mathrm{F} 6,2,3$ & - & - & ++ & ++ & - \\
\hline $\mathrm{F} 6,2,2,3$ & - & - & ++ & ++ & - \\
\hline $\mathrm{F} 64,2$ & ++ & - & ++ & ++ & - \\
\hline $\mathrm{F} 3,2$ & - & + & ++ & ++ & - \\
\hline $\mathrm{F} 7,8$ & ++ & + & ++ & ++ & - \\
\hline $\mathrm{F} 2,1$ & - & + & ++ & ++ & - \\
\hline $2 \mathrm{~F} 2,2$ & ++ & - & ++ & - & - \\
\hline $2 \mathrm{~F} 7,5$ & - & + & + & ++ & - \\
\hline $2 \mathrm{~F} 4,1$ & - & + & ++ & ++ & - \\
\hline $\mathrm{F} 7,1,2$ & - & + & ++ & ++ & - \\
\hline $2 \mathrm{~F} 4,2$ & - & - & + & - & - \\
\hline $2 \mathrm{~F} 5,3$ & ++ & + & +++ & - & - \\
\hline $2 \mathrm{~F} 1,2$ & +++ & + & +++ & +++ & + \\
\hline
\end{tabular}

$(-)$ No growth (+)a small growth(++)growth (+++) large growth

Table 2: Antifungal inhibition spectrum of LAB strains in a dual-culture agar overlay methods.

\begin{tabular}{|c|c|c|c|c|c|c|c|c|c|c|c|}
\hline \multirow{2}{*}{ Tested Molds } & \multirow{2}{*}{ Inhibition } & \multicolumn{10}{|c|}{ Lactic Acid Bacteria } \\
\hline & & $\mathrm{F} 5,4$ & $\mathrm{~F} 7,8$ & $\mathrm{~F} 7,2$ & $2 \mathrm{~F} 5,7$ & $\mathrm{~F} 4,4$ & $2 \mathrm{~F} 7,5$ & $\mathrm{~F} 3,2$ & $\mathrm{~F} 7,4$ & $F 2,1$ & $2 \mathrm{~F} 3,2$ \\
\hline \multirow{2}{*}{ A.parasiticus } & Growth & ++ & ++ & ++ & + & ++ & ++ & ++ & ++ & ++ & ++ \\
\hline & Spore & 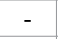 & 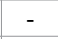 & ++ & ++ & - & - & - & - & - & - \\
\hline \multirow{2}{*}{ P.notatum } & Growth & - & ++ & + & . & +++ & +++ & ++ & 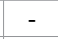 & + & ++ \\
\hline & Spore & ++ & - & ++ & ++ & ++ & ++ & ++ & ++ & ++ & ++ \\
\hline \multirow{2}{*}{ P.roqueforti } & Growth & + & ++ & + & + & + & +++ & ++ & ++ & + & + \\
\hline & Spore & ++ & - & - & ++ & ++ & ++ & ++ & ++ & ++ & ++ \\
\hline \multirow{2}{*}{ P.citrinum } & Growth & ++ & 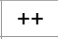 & 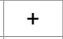 & & ++ & ++ & + & + & ++ & ++ \\
\hline & Spore & - & ++ & ++ & - & - & - & - & - & ++ & ++ \\
\hline \multirow{2}{*}{$\begin{array}{c}P . \\
\text { griseofulvum }\end{array}$} & Growth & ++ & + & + & . & ++ & + & ++ & ++ & ++ & ++ \\
\hline & Spore & ++ & ++ & - & ++ & - & ++ & - & - & - & - \\
\hline \multirow{2}{*}{ A.fumigatus } & Growth & - & - & - & + & - & - & - & - & + & - \\
\hline & Spore & ++ & ++ & ++ & ++ & ++ & ++ & ++ & ++ & ++ & ++ \\
\hline \multirow{2}{*}{$\begin{array}{c}P . \\
\text { chrysogenum }\end{array}$} & Growth & ++ & ++ & ++ & ++ & ++ & - & ++ & ++ & ++ & ++ \\
\hline & Spore & - & - & - & 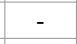 & - & - & - & ++ & ++ & - \\
\hline \multirow{2}{*}{ A. oryzae } & Growth & ++ & ++ & ++ & ++ & ++ & ++ & ++ & ++ & ++ & ++ \\
\hline & Spore & - & ++ & 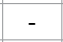 & ++ & ++ & - & - & - & - & - \\
\hline \multirow[t]{2}{*}{ A. alternata } & Growth & + & ++ & +++ & - & - & ++ & +++ & ++ & +++ & ++ \\
\hline & Spore & ++ & ++ & ++ & ++ & ++ & - & ++ & - & ++ & - \\
\hline
\end{tabular}

$(-)$ No inhibition, (+) weak inhibition, $(++)$ inhibition, $(+++)$ strongly inhibition

Table 3: Inhibition of conidia and mycelia growth in the well methods.

11 was reported to inhibit the growth of Fusarium culmorum and $P$. expansum [14].

Changes in P.chrysogenum, P. griseofulvum and E. durans counts during the six days in MRS broth are given Figure 2. The population of P.chrysogenum, $P$. griseofulvum, in the inoculated samples decreased gradually during the six days. The count of P.chrysogenum decreased below the minimum detectable level after $48 \mathrm{~h}$. There for P.chrysogenum was not detected in the medium. P.chrysogenum was more sensitive to metabolites of E. durans. P. griseofulvum exhibited significant tolerance to the medium after 6 days. The count of P. griseofulvum decreased below the minimum detectable level after 6 days (Figure 2).

Figure 3 shows the survival of $A$. fumigatus and A. parasiticus in the MRS broth. The population of A. fumigatus and A. parasiticus decreased gradually during the first four days. The count of $A$. parasiticus was below the minimum detectable level after 6 days. A. fumigatus was not inhibited (Figure 3). Wiseman and Marth [15] demonstrated inhibition of $A$. parasiticus by Streptococcus lactis C10 strain, without identification of the inhibitor agent.

Finally, E. durans completely inhibited the growth of filamentous fungus P.chrysogenum after 48 h. P.griseofulvum and A. parasiticus inhibited after 6 days.

P.chrysogenum, P. griseofulvum, A. parasiticus were almost

\begin{tabular}{|c|c|}
\hline Growth At & Growth In \\
\hline F & Gram reaction \\
\hline+ & Morphology \\
\hline Co & Alpha hemolysis \\
\hline- & Beta hemolysis \\
\hline- & Voges-Proskauer \\
\hline+ & Catalase \\
\hline- & $\mathrm{H}_{2} \mathrm{~S}$ production \\
\hline- & Arginine \\
\hline+ & $4^{\circ} \mathrm{C}$ \\
\hline- & $15^{\circ} \mathrm{C}$ \\
\hline+ & $45^{\circ} \mathrm{C}$ \\
\hline+ & $6.5 \% ~ N a C l$ \\
\hline+ & $7.0 \% ~ N a C l$ \\
\hline+ & $10 \% \mathrm{NaCl}$ \\
\hline- & $\mathrm{pH} 2$ \\
\hline- & $\mathrm{pH} 3.9$ \\
\hline+ & $\mathrm{pH} 9.6$ \\
\hline
\end{tabular}

Table 4: Morphological, cultural, and physiological characteristics of the F 2.1.

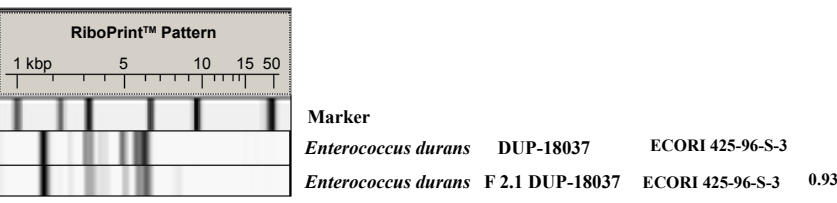

Figure 1: Ribotyping profiles of isolate and standards were shown with DUP numbers.

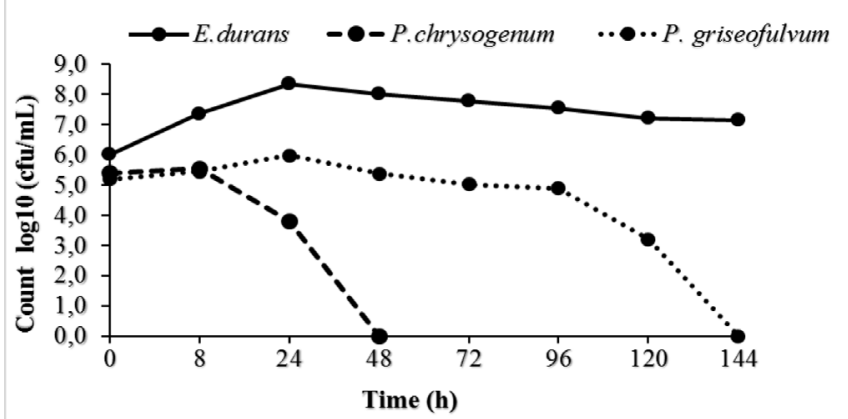

Figure 2: Inhibition of $P$.chrysogenum and $P$. griseofulvum by $E$. durans F2.1 in MRS broth. 


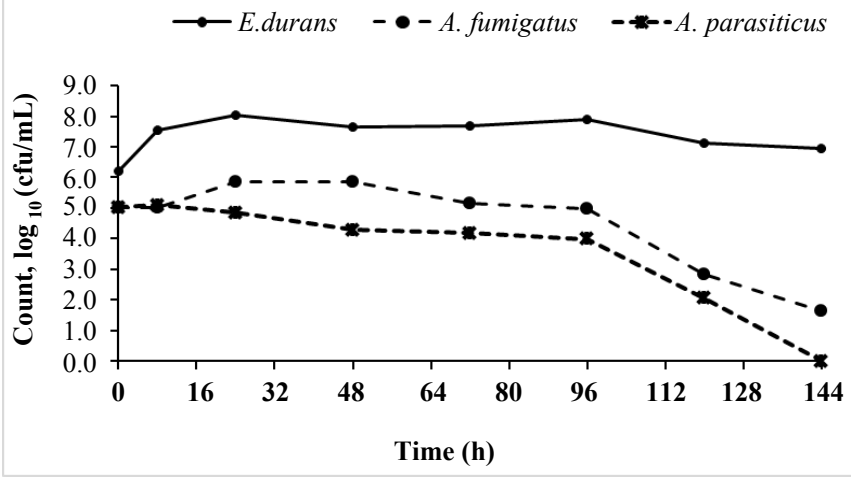

Figure 3: Inhibition of A. fumigatus and A. parasiticus. by E. durans F2.1 in MRS broth.

completely inhibited by $E$. durans. A. fumigatus was shown to be resistant to the $E$. durans. The inhibition of fungal growth showed high sensitivity to evaluate inhibition on all fungal strains tested except $A$. fumigatus.

This is the first report on the antifungal performances of $E$. durans against P.chrysogenum, P. griseofulvum, A. parasiticus.

The inhibitory activity of $E$. durans against tested fungi (P.chrysogenum, P. griseofulvum, A. parasiticus) could be production of proteinaceous substances and organic acids. Belguesmia et al. [14] reported that the antifungal activity of $E$. durans have 2 bacteriocins named duracin. Laitila et al. [16] and Lavermicocca et al. [17] suggested that the antifungal activity of $L$. plantarum could be the results of many organic acids such as lactic, acetic and phenyllactic acids.

More than one compound is responsible for the antimicrobial activity of E.durans. We need further studies to use these compounds alone or in combination for their potential use as food biopreservation. E.durans can be used as starter culture in foods. With this method itself of E.durans can be biopreservation directly, however we also need further studies about E.durans.

\section{Acknowledgments}

The financial support of the research foundation of Anadolu University is gratefully acknowledged.

\section{References}

1. Schnürer J, Magnusson J (2005) Antifungal lactic acid bacteria as biopreservatives. Trends in Food Science and Technology 16: 70-78.
2. Dalie DKD, Deschamps AM, Richard-Forget $F(2010)$ Lactic acid bacteria potential for control of mould growth and mycotoxins: a review. Food Control 21: $370-380$.

3. Ström K, Schnürer J, Melin P (2005) Co-cultivation of antifungal Lactobacillus plantarum MiLAB 393 and Aspergillus nidulans, evaluation of effects on fungal growth and protein expression. FEMS Microbiol Lett 246: 119-124.

4. Gerez Cl, Torino IM, Rollan G, de Valdez FG (2009) Prevention of bread mould spoilage by using lactic acid bacteria with antifungal properties. Food Control 20: 144-148.

5. Stiles ME (1996) Biopreservation by lactic acid bacteria. Antonie van Leeuwenhoek 70: 331-345.

6. Lind $\mathrm{H}$, Jonsson $\mathrm{H}$, Schnürer $\mathrm{J}$ (2005) Antifungal effect of dairy propionibacteria contribution of organic acids. International Journal of Food Microbiology 98 : 157-165.

7. Magnusson J, Schnürer J (2001) Lactobacillus coryniformis subsp. Coryniformis strain $\mathrm{Si} 3$ produces a broad-spectrum proteinaceous antifungal compound. Appl Environ Microbiol 67: 1-5.

8. Schillinger U, Lücke FK (1989) Antibacterial activity of Lactobacillus sake isolated from meat. Appl Environ Microbiol 55: 1901-1906.

9. Stiles ME, Holzapfel WH (1997) Lactic acid bacteria of foods and their current taxonomy. Int J Food Microbiol 36: 1-29.

10. Plockova M, Stilesm J, Chumchalova J, Halfarova R (2001) Control of mould growth by Lactobacillus rhamnosus VT1 and Lactobacillus reuteri CCM 3625 on milk agar plates. Czech J Food Sci 19: 46-50.

11. Muhialdin BJ, Hassan Z (2011) Screening of Lactic Acid Bacteria for Antifungal Activity against Aspergillus oryzae. American Journal of Applied Sciences 8 : 447-451.

12. Roy U, Kaushik JK, Grover-Batish VK (2009) Partial purification of an antifungal protein produced by Enterococcus faecalis CHD 28.3. Ann Microbiol 59: 279284

13. Shekh RM, Singh P, Singh SM, Roy U (2011) Antifungal activity of Arctic and Antarctic bacteria isolates. Polar Biol 34: 139-143.

14. Belguesmia $Y$, Choiset $Y$, Rabesona H, Baudy-Floc'h M, Le Blay G, et al (2012) Antifungal properties of durancins isolated from Enterococcus durans A5-11 and of its synthetic fragments. Lett Appl Microbiol 56: 237-244.

15. Wiseman DW, Marth EH (1981) Growth and aflatoxin production by Aspergillus parasiticus when in the presence of Streptococcus lactis. Mycopathologia 73: 49-56.

16. Laitila A, Alakomi HL, Raaska L, Mattila Sandholm T, Haikara A (2002) Antifungal activities of two Lactobacillus plantarum strains against Fusarium moulds in vitro and in malting of barley. J Applied Microbiol 93: 566-576.

17. Lavermicocca P, Valerio F, Visconti A (2003) Antifungal activity of phenyllactic acid against molds isolated from bakery products. Applied Environ Microbio 69: $634-640$. 